\section{Historians and scientists}

David J. Miller

Pions to Quarks: Particle Physics in the 1950s. Edited by Laurie M. Brown, Max Dresden and Lillian Hoddeson. Cambridge University Press: 1990 . Pp.734. $£ 40, \$ 59.50$.

"THE 1950s" are deemed to start in 1947 and end in 1963: from the discovery that pions, not muons, are the Yukawa particles that carry the nuclear interaction, to the firm establishment of SU(3) theory. This was the exploration stage of particle physics, containing a succession of surprises. Almost as soon as the pion had been identified in the cosmic radiation, the first strange-particle decays were seen. The idea of a weak interaction was developed, with associated production and strangeness. The interaction carried by the pion turned out to be too strong for the perturbation calculations that worked for electromagnetism, so dispersion relations and S-matrix theory drove out field theories for more than a decade. The biggest surprise of all was the discovery of parity violation - first hinted at by the properties of what we now call $\mathrm{K}$ mesons, then proved in nuclear beta-decay.

The backbone of this book is provided by the reminiscences of the physicists who did the work, complemented by contributions from professional historians of science. The right pieces of the story are told by the right people, among them Rochester, Perkins, Yang, Hofstadter, Steinberger, Pais, Pontecorvo, Treiman, Dalitz, Marshak, Schweber, Gell-Mann, Nambu and Ne'eman. Reines discusses the observation of the neutrino, Chamberlain the antiproton, and Chew hadron democracy. There is a great deal of passion in many of the accounts, and much setting the record straight - sometimes unselfishly, as when Blewett and others give credit to the self-taught Greek, Nicholas Christofilos, who invented the story focusing principle ahead of all the specialists. But there are two epic pieces of axe-grinding from great men who still do not feel that they got the credit they deserved - Piccioni, who claims he told Chamberlain and Segre how to search for the antiproton at the Berkeley Bevatron, and Sudarshan, who says that he and Marshak presented a paper on V-A weak-interaction theory at Padova a few months before the work of Feynmann and Gell-Mann appeared.

The historians' contributions are useful, particularly in putting the development of accelerators into their political context in the United States at the height of the cold war, and in their critical examination of the written records, correcting the selective memories of the people who did the work. On the question of why the Berkeley Bevatron was built, Heilbron, a historian, lists a complex of reasons, all of which were true at the time for some of those participating in the decision. The particle physicists claim it was for the sake of pure science, in particular to find the antiproton. But the Atomic Energy Commission was also concerned to keep together Lawrence's team from the "Manhattan Engineering District" that developed the atomic bomb, and to train the next generation of weapons research physicists. At about the same time, the Lawrence Livermore Laboratory was separated from the Lawrence Berkeley Laboratory to build the first stage of a huge linear accelerator - the MTA, or Materials Testing Accelerator - intended to produce fissionable materials for weapons. Blewett, writing about how Brookhaven managed to get the Cosmotron ready before the Berkeley Bevatron, says "We knew nothing about this project; it was completely secret..... So far as we could see, for no visible reason, construction of the Bevatron stopped and its staff disappeared. We asked no questions, but were thankful for the decreased pressure." The historian Seidel gives more details of the MTA project, started in response to the first Soviet nuclear bomb. It never worked properly and was eventually abandoned when the Atomic
Energy Commission discovered that uranium prospecting was a more productive way of building up stocks of nuclear fuel.

Cloud chambers, emulsions and Geiger counters were the principal particle detectors for cosmic-ray work in 1947. By 1963, accelerators had almost completely taken over, the bubble chamber had arrived, spark chambers were growing in importance and new scintillating materials were being used. There are first-hand accounts of how each of these techniques evolved. Electronic computers began to appear and are mentioned in a few of the contributions, particularly in Luis Alvarez's dashing account of how he took Glazer's idea of a small 'clean' glass bubble chamber, applied large-scale engineering and organizational methods and founded the 'industrialized' particle physics of the $1960 \mathrm{~s}$ and $70 \mathrm{~s}$. Galison, a historian, points out that Alvarez had to pull some of the cryogenic experts he needed out of the $\mathrm{H}$-bomb programme to help him build his 72-inch liquid-hydrogen bubble chamber, starting a line of development in which particle physics laboratories still lead the world - particularly in the large-scale application of superconductivity.

This is not only an important book, it is great fun to read. Every physicist should do so.

David J. Miller is in the Department of Physics and Astronomy, University College London, Gower Street, London WC1E 6BT, UK.

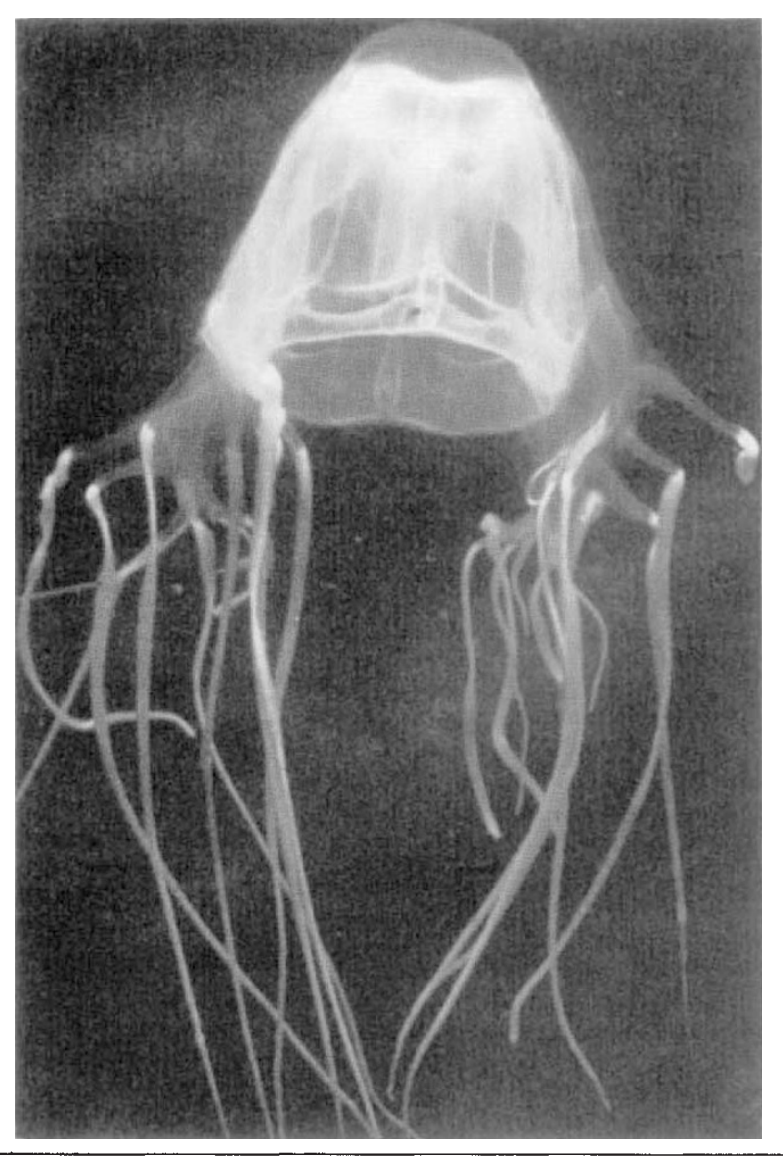

Chironex fleckeri (Southcott) is probably the most dangerous marine animal known, causing death in seconds to minutes. This specimen was found near Cairns, Queensland in Australia, and is one of many species illustrated in Dangerous and Venomous Marine Animals of the World, whose second, revised edition has recently been published. The author, Bruce Halstead, has produced a huge and comprehensive monograph of 1,168 pages of text and 288 of illustrations. Publisher is Darwin, New Jersey. Together with P. S. Auerbach and D. Campbell, Halstead has also just written Dangerous Marine Animals, a lavishly illustrated colour atlas published by Wolfe Medical, price $\$ 29.50$. 